\title{
Analysis on Current Information of Wound Field Synchronous Motor for Electric Vehicle
}

\author{
Young-Chul Shin* and Ki-Chan Kim ${ }^{\dagger}$
}

\begin{abstract}
This paper deals with the effective analysis method of current information of wound field synchronous motor (WFSM) for electric vehicle in order to have high efficiency in driving range. Current information for inverter is divided into three parameters of field current as well as d-axis and q-axis currents of stator windings. First, the search method of current information is showed by separating control regions of constant torque and constant power with each operation point. Finally, efficiency map of whole driving range having high efficiency is proposed by using analyzed current information.
\end{abstract}

Keywords: Current information, Electric vehicle, Field weakening control, WFSM

\section{Introduction}

Wound field synchronous motor (WFSM) is used for traction motor as one of the non-earth magnetic motors. For torque control, WFSM can be controlled by using the field current in addition to d-axis and q-axis currents, which is different from interior permanent magnet synchronous motor (IPMSM) by only using d-axis and qaxis currents [1]. Therefore, for the torque control, it should be controlled on driving range by inputting appropriate field current as well as d-axis and q-axis currents from the vector inverter. There are several current information set for the target torque. However, the maximum efficiency of WFSM is generated at the specific current information. In general, the analysis of WFSM is conducted by using analytical method. However, it is difficult to consider magnetic saturation in a core by analytical method of mathematical model. For the exact analysis of current information for vector inverter, finite element method (FEM) should be used [2-4].

In the paper, the extraction method for current information of WFSM in order to be operated with high efficiency is proposed by using FEM. As an application of traction motor for electric vehicle (EV), the current information for vector inverter corresponds to field current of rotor, d-axis current and q-axis current. Moreover, WFSM is operated with two separated region of constant torque control and constant power control. In the constant power region, it is important to check the terminal voltage not to exceed battery voltage when the current control of vector inverter is conducted. First, the load angle curves according to several field currents and stator currents are analyzed by FEM. Second, the current information at each

$\dagger$ Corresponding Author: Dept. of Electrical Engineering, Hanbat National University, Korea.(kckim@hanbat.ac.kr)

* Dept. of Electrical Engineering, Hanbat National University, Korea (syc3068@naver.com)

Received: December 15, 2015; Accepted: March 18, 2016 operation torque can be extracted from load angle curves satisfying battery voltage level. Finally, the efficiency map can be analyzed by using the current information within operation region $[5,6]$.

\section{Analysis Model}

Compared to IPMSM, the rotor of WFSM consists of a core and field windings instead of a permanent magnet. Field current is applied to the field windings in order to generate field magnetic flux. Torque of WFSM can be generated from (1) by using a field current, $I_{f}$, armature current, $I_{a}$ and the angle of stator current, $\beta$. Inductances of field winding and stator winding have nonlinear characteristic due to magnetic saturation in the cores in the vicinity of air-gap.

$$
T=\frac{3}{2} p\left\{L_{m} I_{f} I_{a} \cos \beta+\left(L_{d}-L_{q}\right) I_{a}^{2} \sin 2 \beta\right\}
$$

For obtaining the current information satisfying target

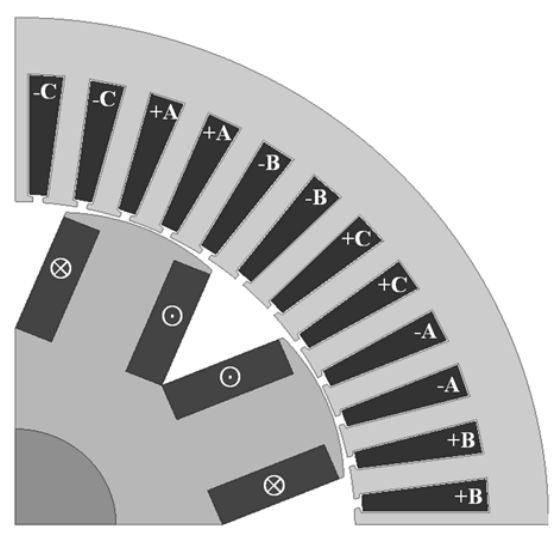

Fig. 1 FEM model for analysis of WFSM 
Table 1. Specifications of WFSM

\begin{tabular}{c|c|c}
\hline Parameter & Value & Unit \\
\hline Number of poles & 8 & - \\
\hline Number of slots & 48 & - \\
\hline Power & 10 & $\mathrm{~kW}$ \\
\hline Rated torque & 32 & $\mathrm{Nm}$ \\
\hline Rated speed & 3,000 & $\mathrm{rpm}$ \\
\hline Max. speed & 6,000 & $\mathrm{rpm}$ \\
\hline Battery voltage & 36 & $\mathrm{~V}_{\mathrm{dc}}$ \\
\hline Phase resistance $\left(\mathrm{R}_{\mathrm{ph}}\right)$ & 0.0051 & $\mathrm{ohm}$ \\
\hline Resistance of field winding $\left(\mathrm{R}_{\mathrm{f}}\right)$ & 3.682 & $\mathrm{ohm}$ \\
\hline
\end{tabular}

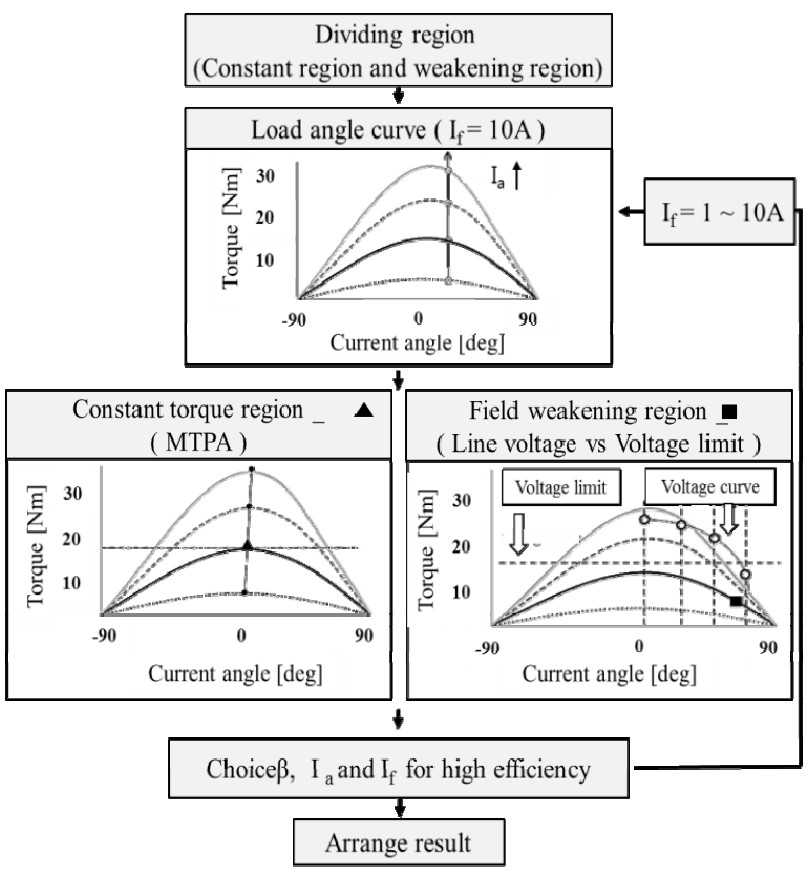

Fig. 2 Flowchart for obtaining the characteristics on the whole driving region

torque, the method for analyzing inductances by FEM is more complicated than the method for analyzing torque directly. Fig. 1 shows analysis model of 10kW WFSM with 8 poles and 48 slots combination for FEM. The battery voltage is $36 \mathrm{Vdc}$, and the limit value of Input current is 330Arms. Detailed specifications of the model are shown in Table 1.

In order to obtain the characteristics on the whole driving region, the operating condition is compared with the others per a driving point because the characteristics such as torque ripple, efficiency, and, power factor vary with the operating condition. However, obtaining the operating conditions on the whole driving region needs to spend a lot of time. Therefore, a flow chart of interpolating each operating condition is proposed as shown in Fig. 2. The analysis method is how to interpolate each operating condition by using the curve on a torque verse load angle. The curve is analyzed by using FEM considering magnetic saturation.

\section{Analysis on Current Information}

For the extraction of current information of WFSM within operation region, the flowchart on proposed method is suggested in Fig. 2. First, operation points of driving torque and speed are selected within operation region in order to analyze the characteristic maps such as efficiency, power factor, current and voltage. If a lot of operation points are selected in this stage, it is good for resolution of maps. However, it is time-consuming work. Second, load angle curves representing torque and load angle between field magnetic flux and stator magnetic flux are calculated from FEM according to several field currents and stator currents. Load angle curves from stator currents are different from each other according to field current due to armature reaction in air-gap. Next, the current information of field current, stator current and current angle is derived by interpolating torque corresponds to each operation point from load angle curves. In this stage, the extraction method of current information is different from control regions such as constant torque region and constant power region. Finally, characteristic maps on efficiency and power factor by using current information can be represented.

\subsection{Operating points within driving region}

For the example of proposed method, the operating points of WFSM are selected as shown in Fig. 3.

Torque step is selected as $4 \mathrm{Nm}$ and speed step is selected as 500rpm within driving region of EV. The number of driving points is 75 .

\subsection{Load angle curves by currents}

First, the load angle curves are analyzed according to stator currents having 40A current step by FEM with fixing field current. Next, another load angle curves with different field current are analyzed by same stator currents. Field current is changed from $1 \mathrm{~A}$ to $16 \mathrm{~A}$ with $1 \mathrm{~A}$ current step. Fig. 4 shows the analyzed load angle curves of $3 \mathrm{~A}$ and $10 \mathrm{~A}$ field currents. If the field current is low, as shown in Fig. 4(a), the current angle of maximum torque at each load

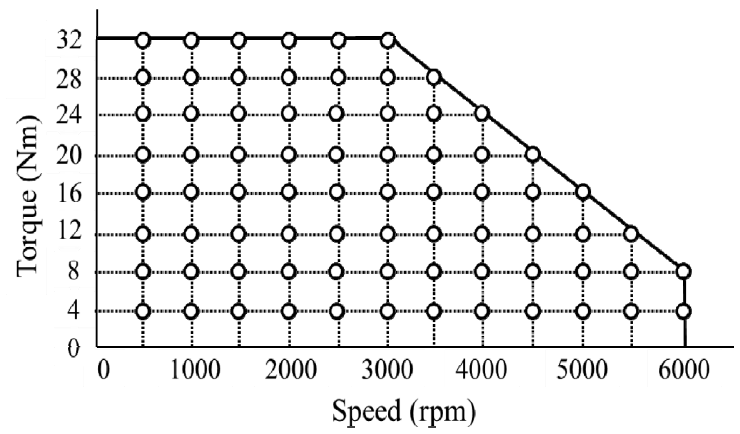

Fig. 3 Selection of driving points for the current information and efficiency on the whole driving region 


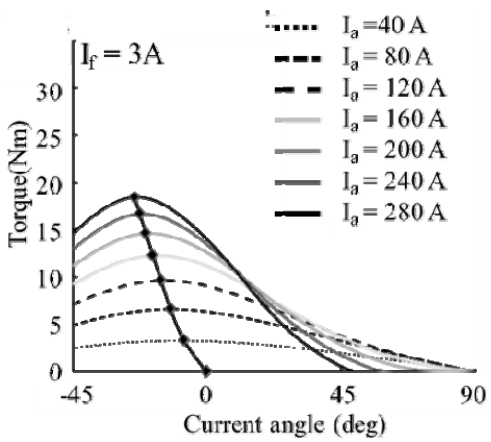

(a) Field current $=3 \mathrm{~A}$

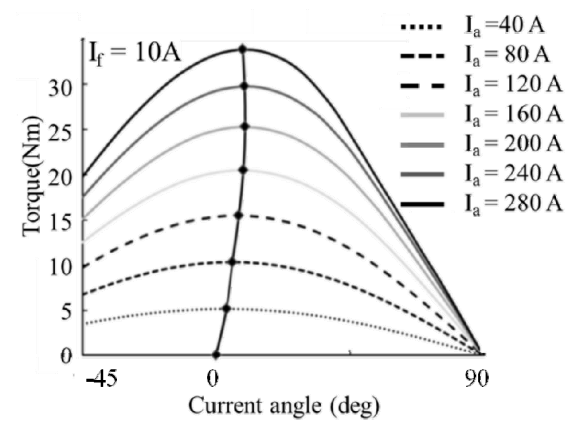

(b) Field current $=10 \mathrm{~A}$

Fig. 4 Load angle curves obtained by using FEM

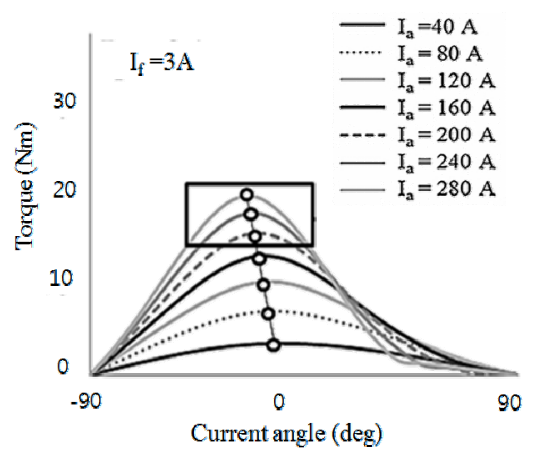

(a) MTPA curve for $I_{f}=3 A$

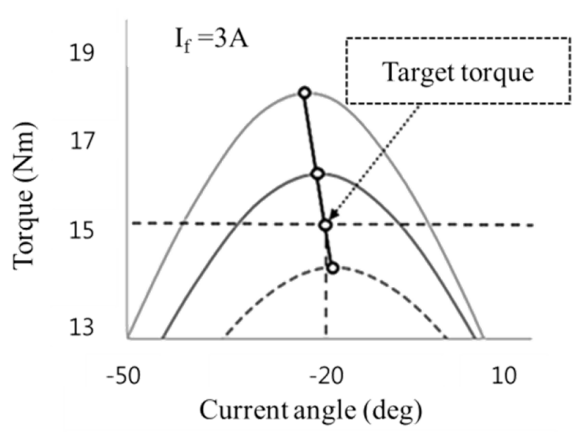

(b) Interpolation for target torque

Fig. 5 Interpolation of load angle curves for MTPA

angle curve is decreased according to the stator current. The load curves are also distorted in the high load angle due to magnetic saturation. On the contrary, if the high

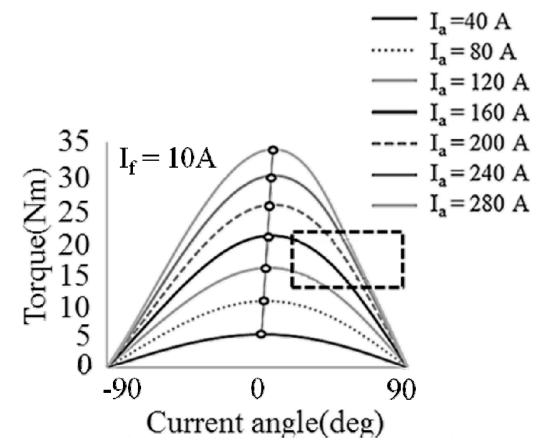

(a) MTPA for $I_{f}=10 A$

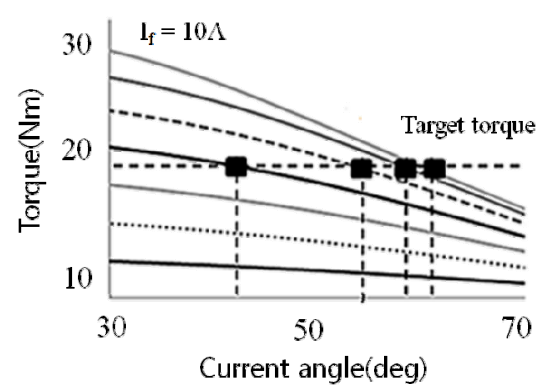

(b) Interpolation for current information

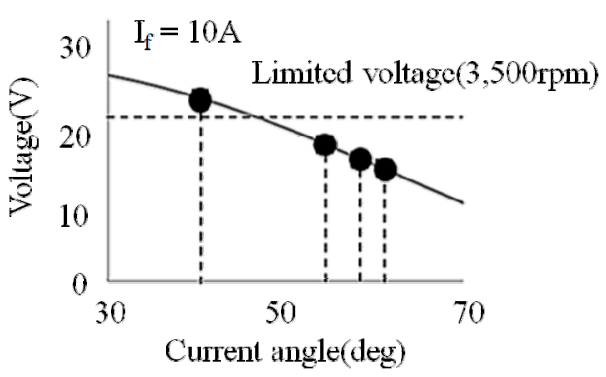

(c) Limited voltage line for 3,500rpm

Fig. 6 Interpolation of load angle curves for field weakening

field current is applied, the current angle of maximum torque is increased, and high torque can be obtained according to stator currents as shown in Fig. 4(b). In case of high torque operation, it is effective to control with high field current and plus current angle. However, in case of low torque operation, operated current information should be selected on the basis of high efficiency.

\subsection{Extraction method of current information}

The current information on the constant torque region is derived by interpolating the load angle curves with target torque. WFSM within the constant torque region is controlled by maximum torque per ampere (MTPA) control for high efficiency due to minimum current under the battery voltage limit. Therefore, the current information at this region can be extracted by interpolating line of MTPA and target torque and comparing efficiencies from the current information according to field currents from $1 \mathrm{~A}$ to $16 \mathrm{~A}$ as shown in Fig. 5. For example, the target torque is 
$16 \mathrm{Nm}$ at $3,000 \mathrm{rpm}$. If field current is $3 \mathrm{~A}$, the target torque is placed between the maximum torque between stator current of 200A and 240A. Therefore, current information is with stator current of $224 \mathrm{~A}$ and current angle of 70 degree.

In case of constant power region, WFSM is controlled with field weakening control by increasing current angle due to limitation of battery voltage. Therefore, input voltage from the current information not to exceed battery voltage should be considered according to motor speed. For example, WFSM is operated with $3,500 \mathrm{rpm}$ and $16 \mathrm{Nm}$ which is an operation point at constant power region. First, several current information crossing the torque line of $16 \mathrm{Nm}$ in load angle curves can be extracted as shown in Fig. 6. At current information, the curve of induced voltage at 3,500 rpm according to current angle can be derived by FEM. Therefore, current information can be calculated by interpolating the point crossing voltage limit and induced voltage. It is also repeated according to field currents for high efficiency.

\section{Characteristic Maps on Driving Region}

Fig. 7 shows the analysis results with two field currents, $3 \mathrm{~A}$ and $10 \mathrm{~A}$, which generate $16 \mathrm{Nm}$ torque and $3,500 \mathrm{rpm}$. In case of field current, 3A, induced voltage exceeding voltage limit is generated due to insufficient flux weakening. However, in case of field current, 10A, induced voltage under voltage limit can be derived. As shown in Table 2, the relevant current information for high efficiency or high power factor can be extracted by using the proposed method.

The current information within driving range can be

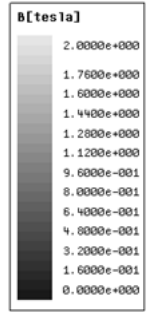

(a) $\mathrm{I}_{\mathrm{f}}=3 \mathrm{~A}$

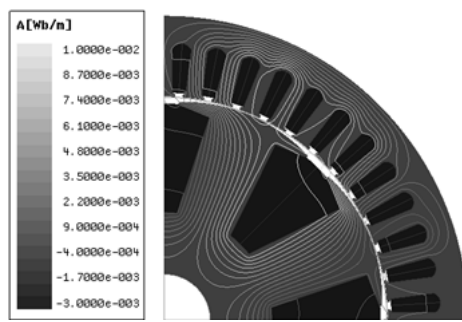

(c) $\mathrm{I}_{\mathrm{f}}=3$

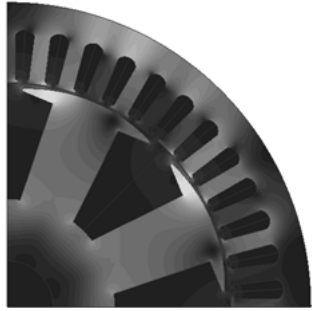

(b) $\mathrm{I}_{\mathrm{f}}=10 \mathrm{~A}$

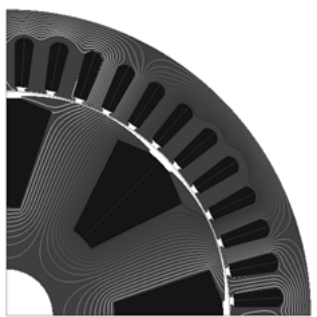

(d) $\mathrm{I}_{\mathrm{f}}=10 \mathrm{~A}$
Fig. 7 Magnetic flux density and flux line according to field current at 3,500rpm
Table 2. Characteristics of a driving point at field weakening control (Torque: 16Nm, Speed: 3,500rpm)

\begin{tabular}{c|c|c|c|c}
\hline $\begin{array}{c}\text { Field current } \\
{\left[\mathrm{A}_{\mathrm{dc}}\right]}\end{array}$ & $\begin{array}{c}\text { Armature } \\
\text { current }\left[\mathrm{A}_{\mathrm{rms}}\right]\end{array}$ & $\begin{array}{c}\text { Current angle } \\
{[\mathrm{deg}]}\end{array}$ & $\begin{array}{c}\text { Efficiency } \\
{[\%]}\end{array}$ & $\begin{array}{c}\text { Power } \\
\text { factor }\end{array}$ \\
\hline 6 & 187 & 28.5 & 92.08 & 0.9237 \\
\hline 7 & 171 & 36.6 & 93.10 & 0.9714 \\
\hline 8 & 178 & 44.5 & 92.65 & 0.9450 \\
\hline
\end{tabular}

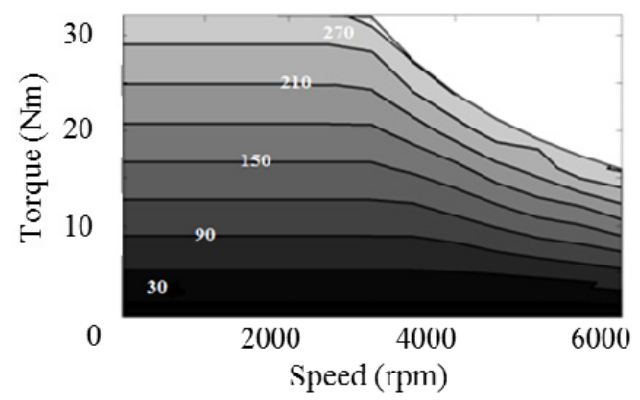

(a) Armature Current

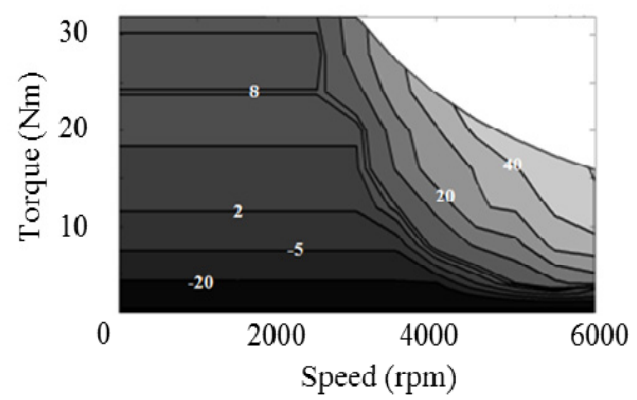

(b) Armature current angle

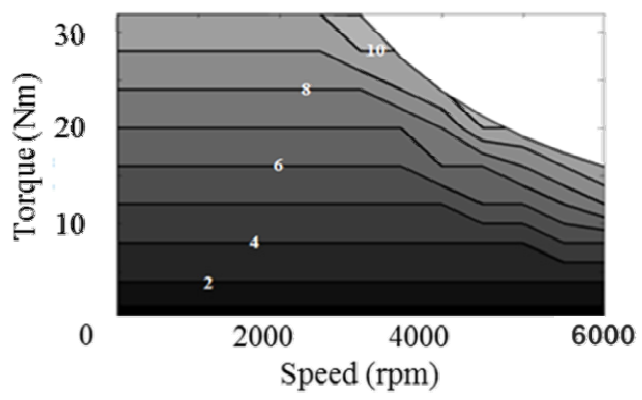

(c) Field current

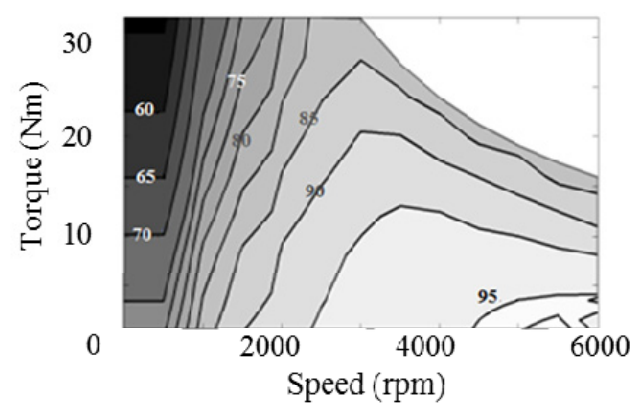

(d) Efficiency

Fig. 8 Efficiency according to current information at the whole driving region 
extracted by iterating the proposed process on 75 operation points. Fig. 8 shows the maps on current information such as field current, stator current and current angle calculated from proposed method for high efficiency and efficiency map when WFSM is controlled with current information within the driving range. It is useful to perform tuning the commands on currents of vector inverter with WFSM.

\section{Conclusion}

In the paper, for the operating WFSM with high efficiency, the effective method for extraction of current information of controller considering is proposed. In order to consider nonlinearity due to magnetic saturation, the proposed method is based on FEM analysis. In case of WFSM, it is important to consider the field current as a control parameter in addition to stator current and current angle which correspond to control parameters of IPMSM. Moreover, WFSM can be controlled when induced voltage from current information is under the value of battery voltage at field weakening control region. It is possible to extract current information of operation with high power factor.

\section{Acknowledgements}

This work was supported by the Technology Innovation Program, 10051652, Development of 80kW Wound Field Synchronous Motor System for Electric Powered Vehicle) funded By the Ministry of Trade, industry \& Energy(MI, Korea)

\section{References}

[1] Michelle L. Bash, Steven D. Pekarek, "Modeling of Salient-Pole Wound-Rotor Synchronous Machines for Population-Based Design," IEEE. Trans. on Energy Convers., vol. 26, pp. 381-392, Jun. 2011.

[2] Huijuan Liu, Longya Xu, "Finite Element Analysis of $1 \mathrm{MW}$ High Speed Wound-Rotor Synchronous Machine," IEEE. Trans. on Magn., vol. 48, pp. 46504653, Nov. 2012.

[3] N. Chen, S. L. Ho, and W. N. Fu, "Optimization of permanent magnet surface shapes of electric motors for minimization of cogging torque using FEM," IEEE. Trans. on Magn., vol. 46, no. 6, pp. 2478-2481, Jun. 2010.

[4] F. Scuiller, "Magnet shape optimization to reduce pulsating torque for a five-phase permanent-magnet low-speed machine," IEEE Trans. Magn., vol. 50, no. 4, pp. 1-9, Apr. 2014.

[5] P. Rasilo, A. Belahcen, and A. Arkkio, "Importance of iron-loss modeling in simulation of wound-field synchronous machines," IEEE Trans. Magn., vol. 48, no. 9, pp. 2495-2504, Sep. 2012.

[6] Park, S, Kim, K.," Torque Ripple Reduction Method with Asymmetric Pole for Wound-Field Synchronous Motor", IEEE. Trans. on Magn., vol. 51, pp. 00189464, March. 2015.

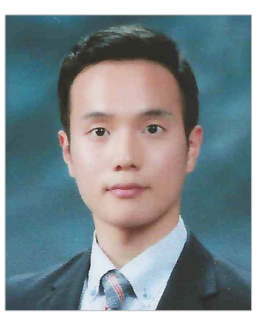

Young-Chul Shin He received B.S degree in electrical engineering from Hanbat National University, Daejeon, Korea in 2015. His research interests are design and analysis of electrical machinery.

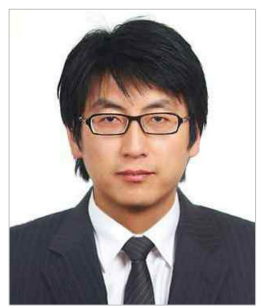

Ki-Chan Kim He received his B.S., M.S., and Ph.D. degrees in Electrical Engineering from Hanyang University, Seoul, Korea in 1996, 1998 and 2005, respectively. He worked for Hyundai Heavy Industries Co., Ltd. from 1998 to 2005. Currently, he is an Associate Professor in Electrical Engineering at Hanbat National University, Daejeon, Korea. His special area of interest includes the design and analysis of electrical motor and sensors. 